\title{
Loss Reduction Method for the Isolated qZS-based DC/DC Converter
}

\author{
Janis Zakis (Senior Research Fellow, Riga Technical University), \\ Ivars Rankis (Professor, Riga Technical University), Liisa Liivik (PhD student, Tallinn University of Technology)
}

\begin{abstract}
This paper presents an isolated quasi-Z-source inverter-based (qZSI) resonant DC/DC converter. The explanation of selection of the proposed topology is justified. Both the normal and the boost modes are discussed. Theoretical operation waveforms as well as basic expressions for the calculation of currents and voltages are proposed. A $1500 \mathrm{~W}$ laboratory prototype was built and experimentally verified at two operation points: that of light-load $(300 \mathrm{~W})$ and full-load $(1500$ W). All the experiments were also carried with resonant circuit and without it. The experimental results as well as performance of proposed qZSI based resonant DC/DC converter laboratory setup are presented and analyzed. Experimental and calculated characteristics showing the dependence of the load voltage and supply current on the load resistance in both modes were presented. The dynamic losses in the transistors were evaluated for the cases with the resonant circuit and without it. The main conclusions based on this study are summarized and the future tasks for development of proposed converter were defined.
\end{abstract}

Keywords - DC-DC power converters, resonant inverters, zero current switching, zero voltage switching.

\section{INTRODUCTION}

In recent years the most challenging tasks for power electronics engineers are connected with efficiency enhancement in switch mode converters.

Focus here is on an efficiency enhancement method for the quasi-impedance-source based (qZS-based) DC/DC converter. According to earlier papers [1-6], the qZS converter has many advantages over other DC/DC converters, such as voltage step-up property in a single stage, continuous input current, excellent immunity of cross-conduction of both switches of one inverter leg, etc. However, very common drawback in all switch mode converters that are coupled with inverters are the dynamic losses during the commutation process of inverter bridge switches $[3,4,7,8]$.

For this reason resonant converters are used due to high efficiency, high switching frequency and high power density.
The operation and differences of series resonant converter and parallel resonant converter were studied a lot [9-12]. Each of those converters has its pros and cons [13].

The idea of this paper is to combine advantages of qZSI based DC/DC converter and resonant converter. Series resonant converter topology is the simplest and widely used $[9,10,14]$ and will be selected for more detailed study.

Fig. 1 presents the proposed converter which consists of qZS-network $\left(L_{1}, L_{2}, C_{1}, C_{2}, D\right)$ coupled with an inverter $\left(T_{1}\right.$,$T_{4}$ ), a resonant circuit $\left(L_{r}\right.$ and $\left.C_{r}\right)$, a transformer $(T R)$, a voltage doubler rectifier $\left(D_{1}, D_{2}, C_{3}, C_{4}\right)$ and a load $\left(R_{l d}\right)$. The operation of the converter depends on the input voltage $\left(U_{1}\right)$. If it is at its rated level and equal to $U_{D C}$, then the converter works as a conventional voltage source inverter (VSI), but if $U_{1}<U_{D C}$, then the shoot-through switching state of the inverter switches (cross-conduction of both switches of one inverter leg) is introduced [1-6, 15]. By adjusting a proper shootthrough duty-cycle of inverter switches $\left(D_{S}\right)$, the DC-link voltage $U_{D C}$ can be kept on the predefined level.

This paper shows how to improve the efficiency of an inverter by introducing the resonant elements $\left(L_{r}\right.$ and $\left.C_{r}\right)$ [16] in the transformer circuit.

\section{Operation MOdes of PROPOSED CONVERTER}

\section{A. Normal Mode}

In this operation mode the input voltage is equal to the DClink voltage $\left(U_{1}=U_{D C}\right)$. The switching frequency of inverter switches is equal to the resonant frequency $\left(f_{S W}=f_{r}\right)$ and can be defined as

$$
f_{S W}=f_{r}=\frac{1}{2 \pi} \sqrt{\frac{1}{L_{r} C_{r}}},
$$

where $L_{r}$ and $C_{r}$ are resonant inductor and capacitor respectively.

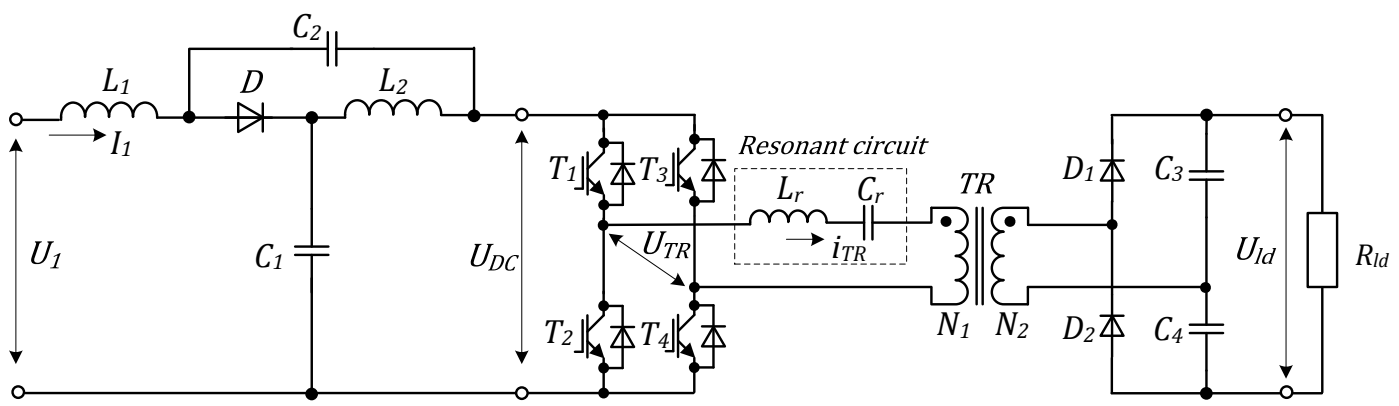

Fig. 1. General circuit diagram of the proposed converter 


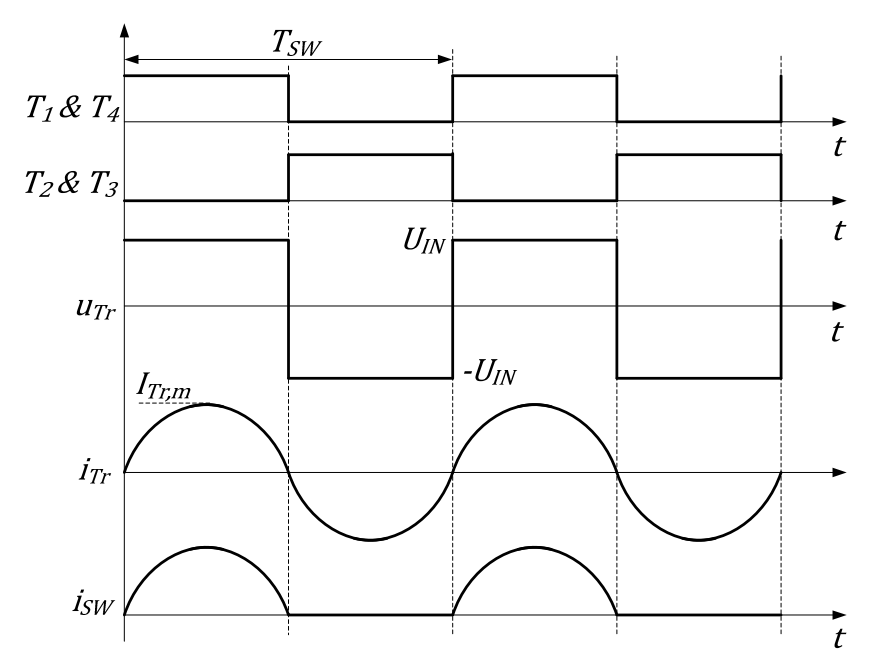

Fig. 2. Theoretical operation waveforms of the proposed converter in the normal operation mode.

Fig. 2 shows the theoretical operation waveforms of the resonant qZSI based converter. Switches here can be turned on and off at almost perfect zero voltage and zero current condition. Therefore, in this mode, maximum efficiency can be achieved.

In such operation mode the current in the resonant circuit can be assumed as a sine wave but the total voltage across both reactive elements is zero. It is assumed that diagonal switches $\left(T_{1}, T_{4}\right.$ and $\left.T_{2}, T_{3}\right)$ are conducting half the period. At the current $i_{T R}>0$, the voltage applied to the resonant circuit is

$$
U_{r}=U_{1}-0.5 U_{l d} \cdot k_{T R},
$$

where $U_{l d}$ is the load voltage and $k_{T R}=N_{1} / N_{2}$ is the transformer turns ratio. This voltage is also applied to the resistance $R_{r}$ that is actually the resistance of the resonant circuit. The load voltage $U_{l d}$ in the circuit diagram in Fig. 1 can be expressed as

$$
U_{l d}=\frac{I_{T R, m} \cdot k_{T R} \cdot R_{l d}}{\pi} .
$$

Average current per half cycle of the resonant circuit is

$$
I_{T R}=\frac{2 \cdot I_{T R, m}}{\pi},
$$

but the input power is $P_{1}=U_{1} \cdot I_{1}$. Therefore, the power balance of the resonant circuit-load can be expressed as

$$
\frac{2 I_{T R, m}}{\pi} \cdot U_{1}-\frac{I_{T R, m}^{2}}{2} \cdot R_{r}=\frac{I_{T R, m}^{2} \cdot k_{T R}^{2} \cdot R_{l d}}{\pi^{2}} .
$$

The amplitude of the resonant circuit current can be found as

$$
I_{T R, m}=\frac{4 \cdot \pi \cdot U_{1}}{\pi^{2} R_{r}+2 R_{l d} \cdot k_{T r}^{2}} .
$$

Using the current of the resonant circuit $\left(I_{T R}\right)$ allows finding load voltage, load power, input power, loss power and also the amplitude value of the capacitor voltage:

$$
U_{C m}=I_{C m} \cdot \sqrt{\frac{L_{r}}{C_{r}}}
$$

where $\sqrt{\frac{L_{r}}{C_{r}}}$ is the resonant impedance.

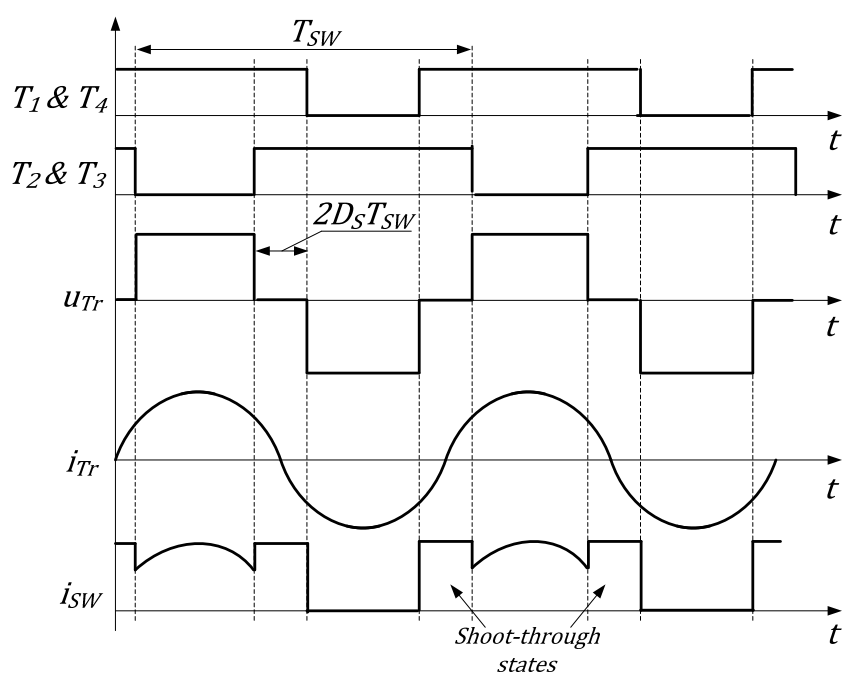

Fig. 3. Theoretical operation waveforms of the proposed converter in the boost operation mode.

\section{B. Boost mode}

If the input voltage of the converter drops below the rated value, the shoot-through switching state of inverter switches is introduced to boost the input voltage $[1-5,15]$.

Also, in this operation mode the switching frequency of inverter switches $f_{S W}$ is fixed to the resonant frequency $f_{r}$. Fig. 3 shows general operation waveforms in the boost operation mode. Here the shape of the resonant circuit current $\left(I_{T R}\right)$ can also be assumed as a sine wave and then the connection between the amplitude value of this current and the load voltage can be described using (3).

Power losses in the resonant circuit resistance $R_{r}$ can be calculated as $0.5 \cdot I_{T R, m}^{2} \cdot R_{r}$. However, extra power losses from the shoot-through state of the qZSI appear here, which can be described as $I_{1}^{2} \cdot R_{q Z S}$, where the supply current $I_{1}$ can be calculated as

$$
I_{1}=\frac{2 \cdot I_{T R, m}}{\pi\left(1-2 \cdot D_{S}\right)},
$$

where $R_{q Z S}$ is an equivalent resistance of the qZS-network during the shoot-through state.

The power balance of the circuit can be categorized as

$$
P_{1}=\Delta P_{q Z S}+\Delta P_{R r}+P_{l d} .
$$

Inserting corresponding expressions in the power balance expression (10), the amplitude of the current of the resonant circuit can be expressed as

$$
I_{T R, m}=\frac{4 \cdot U_{1} \pi\left(1-2 D_{S}\right)}{8 R_{q Z S}+2 k_{T r}^{2} R_{l d}\left(1-2 \cdot D_{S}\right)^{2}+\pi^{2} R_{r}(1-2 D s)^{2}} .
$$

\section{EXPERIMENTAL VERIFICATION}

To evaluate the operation of the proposed converter (Fig. 1) an experimental setup was built. General circuit parameters are summarized in Table I. We made our experiments at two operation points: at light load $(300 \mathrm{~W})$ when the input voltage is equal to the rated voltage and at full load $(1500 \mathrm{~W})$ when 
TABLE I

General Operating Parameters, Component Types and Values

\begin{tabular}{|c|c|}
\hline Operating parameters & Value/type \\
\hline Nominal input voltage, $U_{1, \text { nom }}$ & $50 \mathrm{~V}$ \\
\hline Minimal input voltage, $U_{1, \min }$ & $25 \mathrm{~V}$ \\
\hline DC-link voltage, $U_{D C}$ & $50 \mathrm{~V}$ \\
\hline Output voltage, $U_{l d}$ & $550 \mathrm{~V}$ \\
\hline Switching frequency, $f_{S W}$ & $23 \mathrm{kHz}$ \\
\hline Components & $1: 6$ \\
\hline$k_{T R}$ & $14.5 \mu \mathrm{H}$ \\
\hline$L_{r}$ & $3 \mu \mathrm{F}$ \\
\hline$C_{r}$ & $\mathrm{maxim}$ \\
\hline
\end{tabular}

the input voltage is a half of the rated and the maximal shootthrough duty cycle $\left(D_{S}\right)$ of inverter switches should be introduced. The shoot-through state is created by overlapping of active states [15]. The switching conditions of all switches in this case are equal.

\section{A. Experiments with a load power of $300 \mathrm{~W}$}

Here we present general waveforms of the converter in light-load operation when the input voltage is at its rated value $(50 \mathrm{~V})$

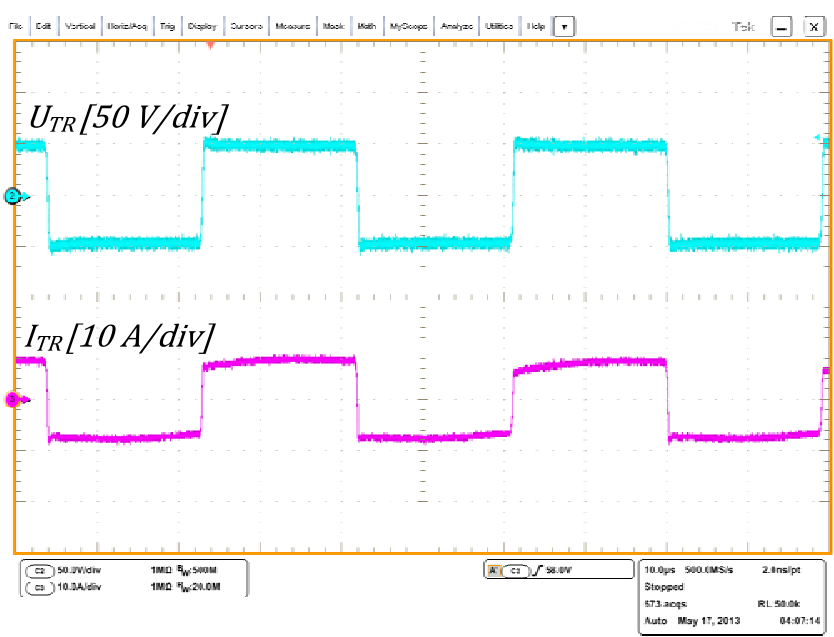

(a)

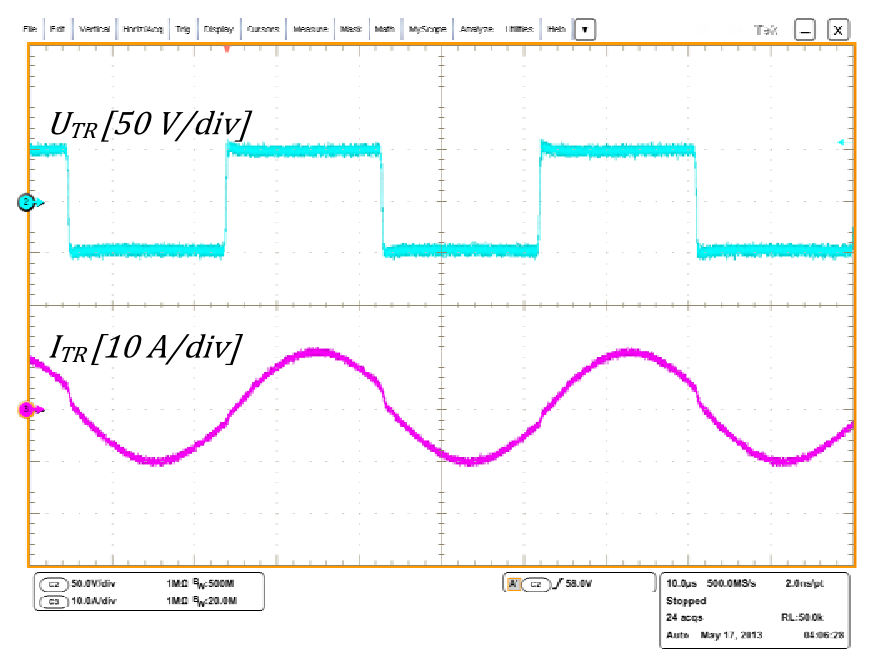

(b)

Fig. 4. Transformer voltage and current of the proposed converter in the normal mode: without the resonant circuit (a) and with the resonant circuit (b).

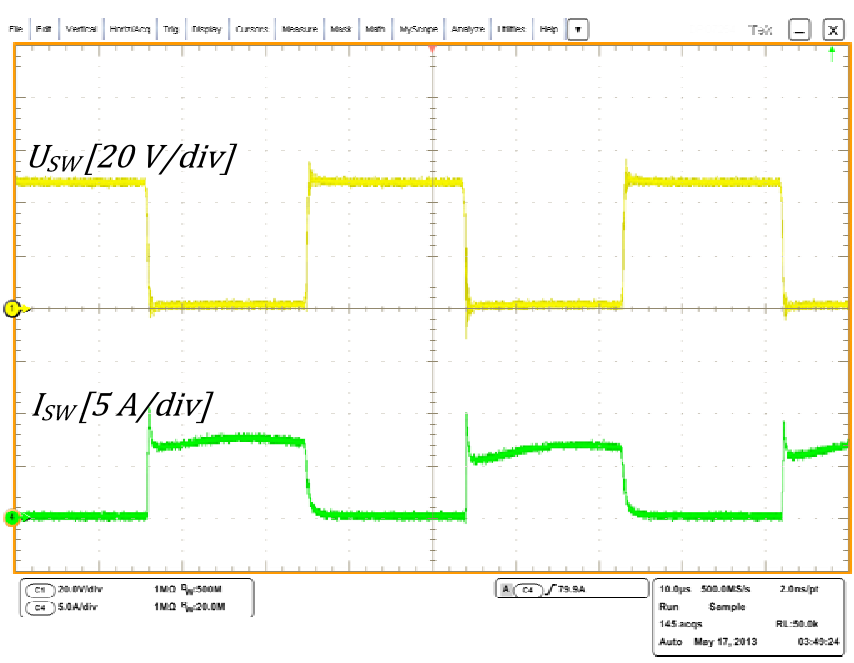

(a)

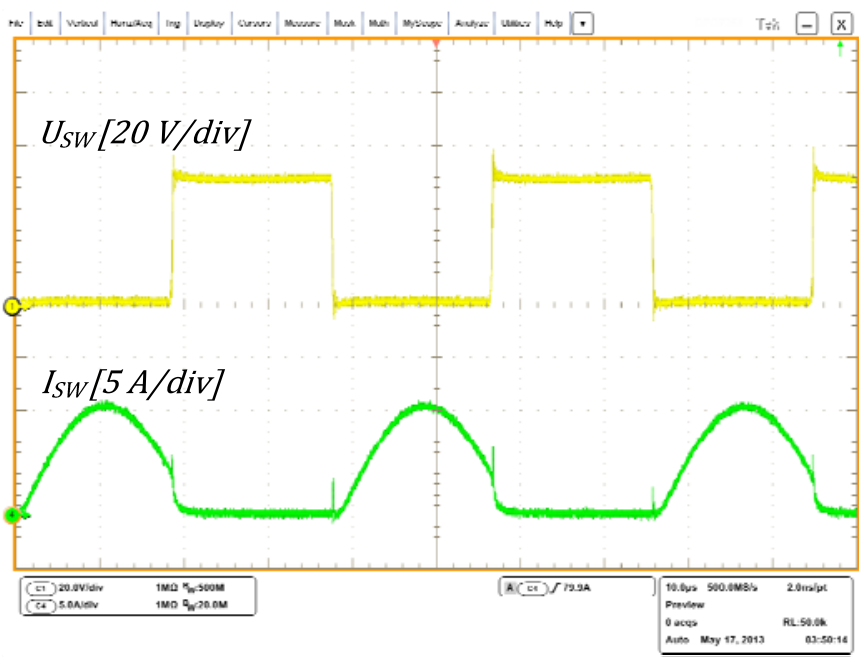

(b)

Fig. 5. Voltage and current of one transistor in the normal mode: without the resonant circuit (a) and with the resonant circuit (b).

Fig. 4(a) shows the transformer voltage $\left(U_{T R}\right)$ and the current $\left(I_{T R}\right)$ without the resonant circuit, but Fig. 4(b) - with the resonant circuit.

As it can be seen, the current form of the transformer is close to a sine wave. In this operation mode the maximal efficiency can be achieved.

Fig. 5(a) shows the transistor switch voltage $\left(U_{S W}\right)$ and the current $\left(I_{S W}\right)$ without the resonant circuit, but Fig. 5(b) - with the resonant circuit.

As it can be seen, the resonant circuit can provide turn-on and -off of the switch at almost perfect zero voltage and zero current condition.

\section{B. Experiments with a load power of $1500 \mathrm{~W}$}

Fig. 6(a) shows the transformer voltage $\left(U_{T R}\right)$ and the current $\left(I_{T R}\right)$ without the resonant circuit, but Fig. 6(b) - with the resonant circuit.

As shown, the resonant circuit can reduce transformer voltage oscillations during the shoot-through state of inverter switches. However, voltage spikes are greater with the resonant circuit. 


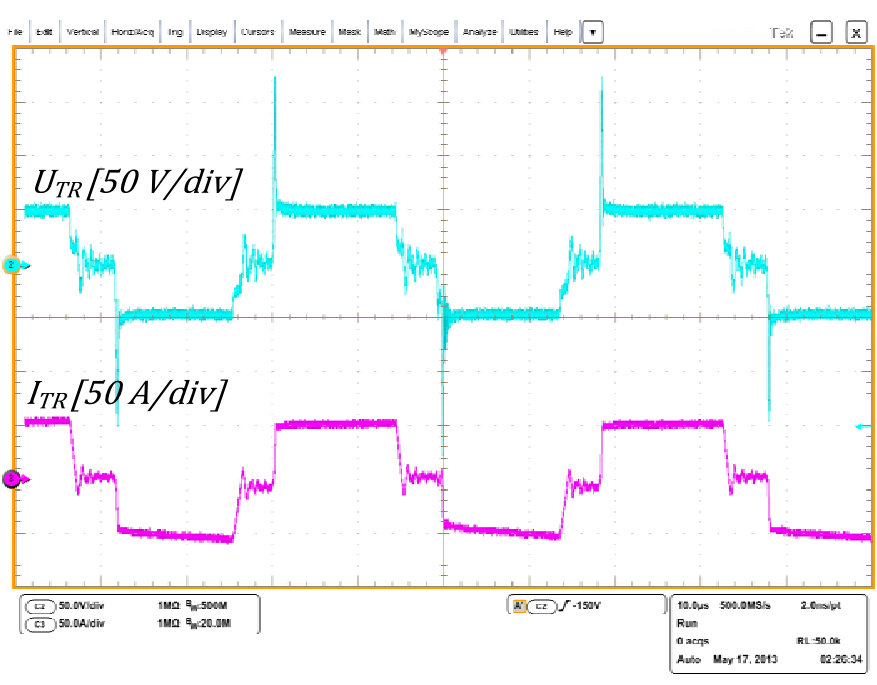

(a)

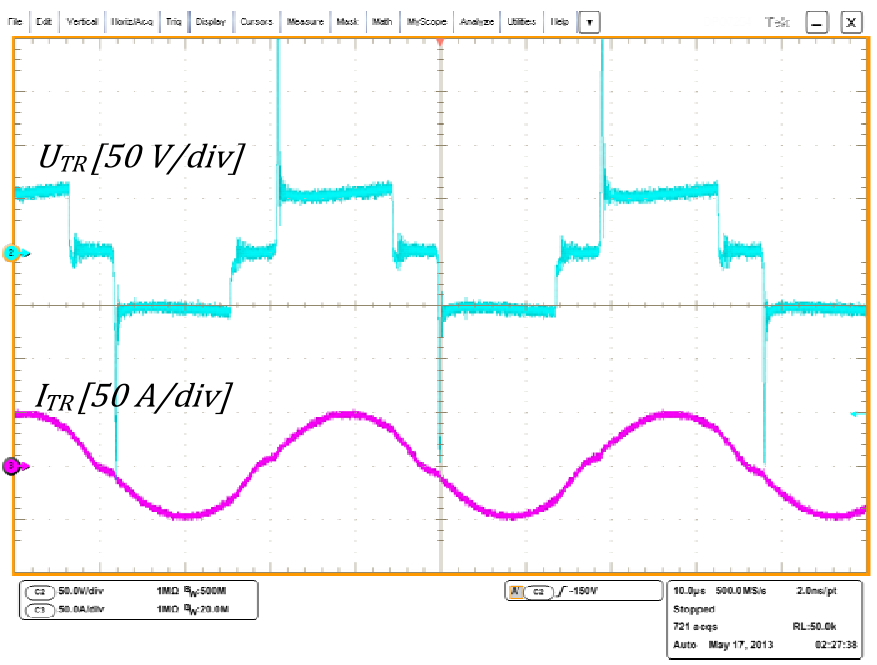

(b)

Fig. 6. Transformer voltage and current of the proposed converter in the boost mode: without the resonant circuit (a) and with the resonant circuit (b).

Fig. 7(a) shows the transistor switch voltage $\left(U_{S W}\right)$ and the current $\left(I_{S W}\right)$ in the boost operation mode without the resonant circuit, but Fig. 7(b) - with the resonant circuit.

\section{VERIFICATION OF THEORETICAL EXPRESSIONS}

\section{A. Normal Mode}

The simplified equations obtained can be verified using the results of our experimental investigation, which for the scheme and regime were made at $U_{1}=50 \mathrm{~V}$, operation frequency $f_{S W}=23 \mathrm{kHz}$, which corresponds to the applied parameters of the resonant circuit $C_{\mathrm{r}}=3 \mu \mathrm{F}, L_{r}=14.5 \mu \mathrm{H}$ and different values of the load resistance $R_{l d}$. Transformer windings ratio is $k_{T R}=1 / 6$. Power measurements of the circuit show that an equivalent resistance of the resonant circuit in this case is $R_{r}=0.254 \Omega$. Fig. 8 presents experimental and

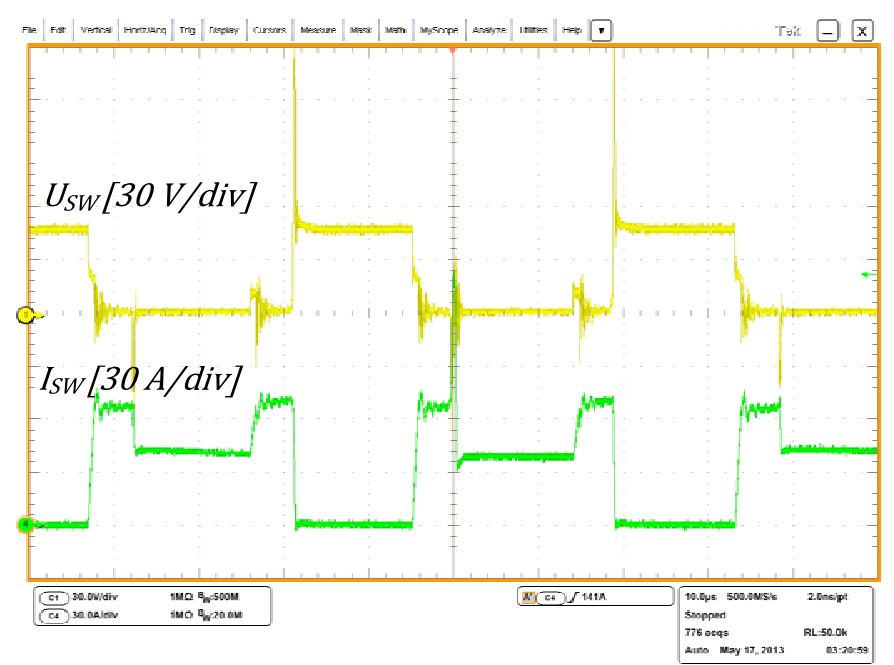

(a)

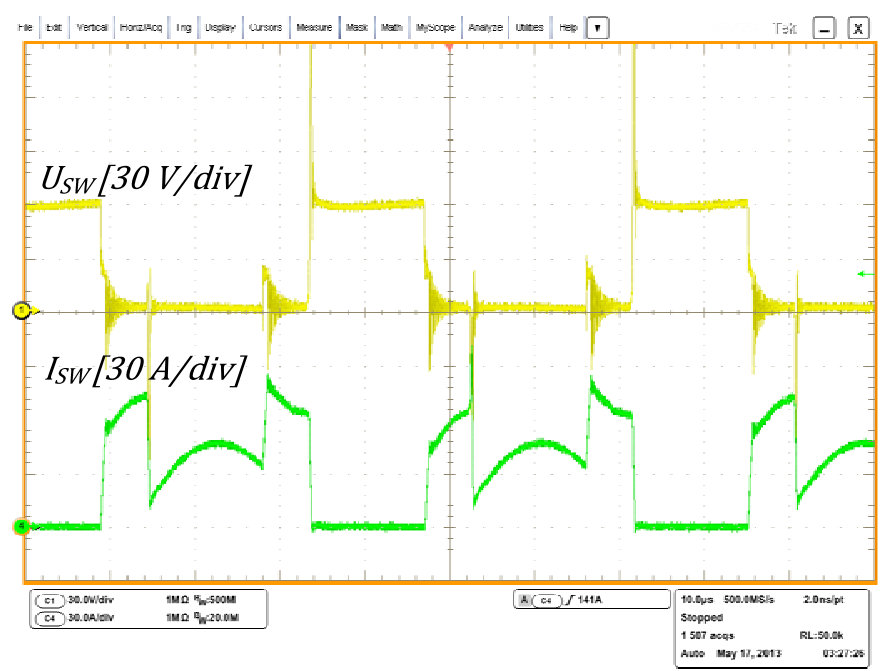

(b)

Fig. 7. Voltage and current of one transistor in the boost mode: without the resonant circuit (a) and with the resonant circuit (b).

calculated characteristics $\left(U_{l d}=f\left(R_{l d}\right)\right.$ and $\left.I_{1}=f\left(R_{l d}\right)\right)$ depending on the load resistance $R_{l d}$. As it can be seen, the calculated characteristics almost correspond to those experimentally obtained that confirms the applicability of the simplified expressions obtained. Calculated amplitudes of the current through resonant circuit change from $61.12 \mathrm{~A}$ at $R_{l d}=140 \Omega$ to $13.38 \mathrm{~A}$ at $R_{l d}=800 \Omega$, creating the amplitude of the resonant capacitor voltage respectively from $134.4 \mathrm{~V}$ to $29.42 \mathrm{~V}$. Rather high value of the resistance of the resonant circuit caused by the skin effect at a relatively high switching frequency indicates a high power loss in the resonant inductor and causes its heating. To reduce power losses in the resonant inductor $L_{r}$ it is recommended to pay attention to the crosssection of the conductor in the winding. Also, Litz wire or foil would be more preferable due to the skin effect at high frequencies $[15,16]$ 

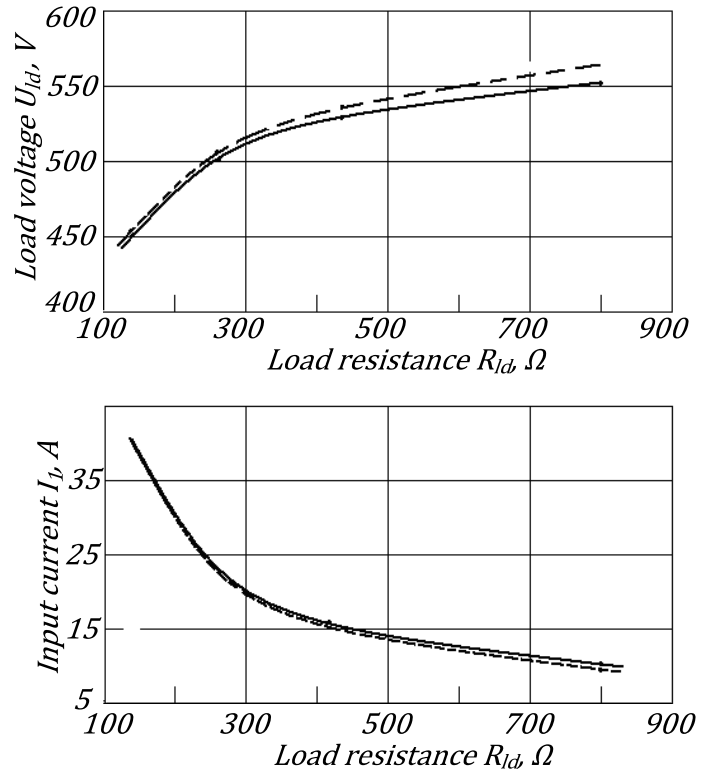

Fig. 8. Experimental and calculated (dashed lines) characteristics showing the dependence of the load voltage $U_{l d}$ and the supply current $I_{1}$ on the load resistance $R_{l d}$ in the normal mode.
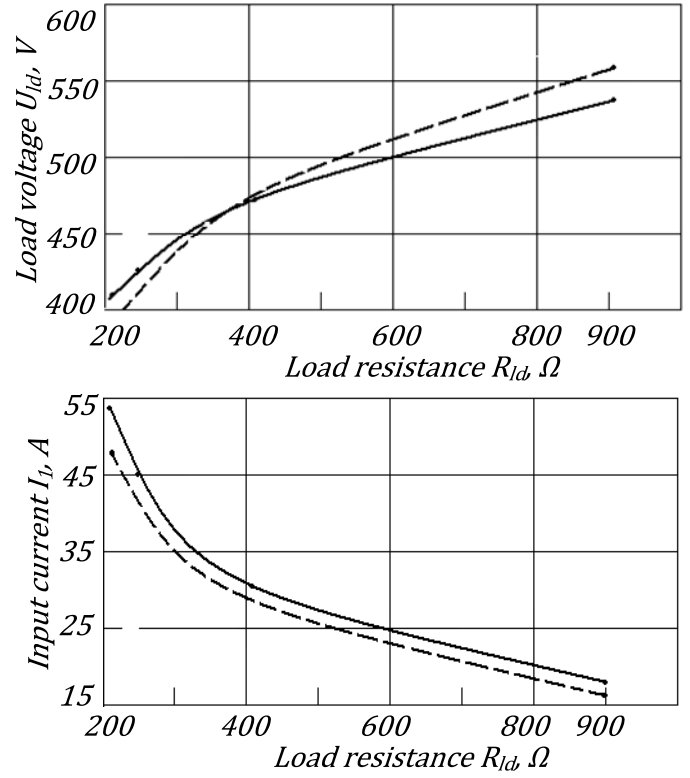

Fig. 9. Experimental and calculated (dashed lines) characteristics showing the dependence of the load voltage $U_{l d}$ and the supply current $I_{1}$ on the load resistance $R_{l d}$. in the boost mode.

TABLE II

DYNAMIC POWER LOSSES AT $P=300 \mathrm{~W}$

\begin{tabular}{|c|c|c|c|}
\hline \multicolumn{4}{|c|}{$P=300 \mathrm{~W}, U_{I N}=50 \mathrm{~V}$} \\
\hline \multicolumn{2}{|c|}{ With resonant circuit } & \multicolumn{2}{c|}{ Without resonant circuit } \\
\hline$P_{\text {ON }},(W)$ & $P_{\text {OFF }},(W)$ & $P_{\text {ON }},(W)$ & $P_{\text {OFF }},(W)$ \\
\hline 0.07 & 2.35 & 0.37 & 2.2 \\
\hline
\end{tabular}

TABLE III

DYNAMIC POWER LOSSES AT $P=1500 \mathrm{~W}$

\begin{tabular}{|c|c|c|c|}
\hline \multicolumn{4}{|c|}{$P=1500 \mathrm{~W}, U_{I N}=32 \mathrm{~V}$} \\
\hline \multicolumn{2}{|c|}{ With resonant circuit } & \multicolumn{2}{|c|}{ Without resonant circuit } \\
\hline$P_{O N},(W)$ & $P_{O F F},(W)$ & $P_{O N},(W)$ & $P_{O F F},(W)$ \\
\hline 0.2 & 26.7 & 8.8 & 42.1 \\
\hline
\end{tabular}

\section{B. Boost Mode}

The simplified equations obtained can be verified using the results of our experimental investigation, which for the scheme and boost mode were conducted at $U_{1}=25 \mathrm{~V}$, operation frequency $f_{S W}=23 \mathrm{kHz}$, which complies with the applied parameters of the resonant circuit $C_{r}=3 \mu \mathrm{F}, L_{r}=14.5 \mu \mathrm{H}$ and different values of the load resistance $R_{l d}$. Transformer windings ratio $k_{T R}=1 / 6$. Power measurements of the circuit show that an equivalent resistance of the qZS-network in this case is $R_{q Z S}=0.15 \Omega$, but the resistance of the resonant circuit is the same as in the previous case (normal mode), i.e. $R_{r}=0.254 \Omega$.

In the experiments, the shoot-through duty cycle accepted was $D_{S}=0.27$. Fig. 9 presents the experimental and the calculated $U_{l d}=f\left(R_{l d}\right), I_{1}=f\left(R_{l d}\right)$ characteristics.

Fig. 9 shows that the calculated and the experimentally obtained characteristics agree sufficiently well for the accepted application. It means that the obtained expressions can be used for rough engineering calculations. Similarly to the normal operation mode, load voltage is increasing with the rise of load resistance but the input current is decreasing. Also, relations of load voltage and supply voltage in the boost mode and input currents at the respective values of load resistance increase.

\section{Evaluation OF POWER LOSSES IN TRANSISTORS}

This section describes the impact of the resonant circuit on dynamic power losses in transistors switches of the inverter bridge $\left(T_{1}-T_{4}\right)$. Since the commutation processes of all transistors of the inverter bridge are equal, Tables II and Table III show the dynamic power losses only in one transistor. The experimental measurements of power losses in the transistor during turn-on and -off were made with Tektonix DPO 7254 oscilloscope and afterward processed in MS Exel.

It is obvious that the implementation of the resonant circuit reduces dynamic power losses in inverter switches. Tables II and III show that the resonant circuit implemented almost eliminates the switching-on losses of the transistor in both operation modes.

\section{CONCLUSIONS AND FUTURE WORK}

This paper has proposed a qZSI based step up resonant $\mathrm{DC} / \mathrm{DC}$ converter that is very promising in a very wide input voltage or load range. In spite of the additional resonant elements introduced in the transformer circuit the proposed converter performs the voltage step-up and step-down features.

The expressions used allow us to obtain a rough calculation of the converter parameters. Also, theoretical waveforms are in good agreement with those experimentally obtained.

Experimental waveforms show that the introduction of resonant elements in the transformer circuit excludes voltage oscillations in the transformer voltage during the shootthrough state. 
The resonant circuit implemented enables us to achieve transistor commutation at almost perfect zero voltage and zero current conditions in the normal mode and reduced dynamic losses in the boost mode. According to Table II and III, the dynamic power losses during the turn-on of the transistor are almost eliminated but during the turn-off of the transistor the losses are reduced up to $40 \%$. Due to the reduction of dynamic losses it is possible to increase the switching frequency and increase the power density of the converter in the future.

The future work will focus on the reduction of power losses in magnetic components, especially in the resonant circuit of the proposed converter topology.

\section{ACKNOWLEDGMENT}

This research work has been supported by Latvian Council of Science (Grant 416/2012).

\section{REFERENCES}

[1] Yuan Li; Anderson, J.; Peng, F.Z.; Dichen Liu, "Quasi-Z-Source Inverter for Photovoltaic Power Generation Systems", Twenty-Fourth Annual IEEE Applied Power Electronics Conference and Exposition APEC 2009, pp. 918-924, 15-19 Feb. 2009.

[2] Vinnikov, D.; Roasto, I.; Zakis, J.; Strzelecki, R.: New Step-Up DC/DC Converter for Fuel Cell Powered Distributed Generation Systems: Some Design Guidelines", in journal "Electrical Review" ISSN 0033-2097, Vol. 86., Nr 8., 2010, pp. 245-252.

[3] Zakis, J.; Vinnikov, D.; Roasto, I., "Soft-switching capability analysis of a qZSI-based DC/DC converter," Electronics Conference (BEC), 12th Biennial Baltic, pp.301-304, 4-6 Oct. 2010.

[4] Fang Zheng Peng, "Z-source inverter", IEEE Transactions on Industry Applications, vol.39, no.2, pp. 504-510, Mar/Apr 2003.

[5] J. Zakis and D. Vinnikov, "Implementation Possibilities of SMD Capacitors for High Power Applications," Electrical, Control and Communication Engineering, vol. 1, no. 1, pp. 18-23, Jan. 2012. ISSN 22559140.

[6] C. Roncero-Clemente, E. Romero-Cadaval, O. Husev, D. Vinnikov, and S. Stepenko, "Simulation of Grid Connected Three-Level Neutral-PointClamped qZS Inverter using PSCAD," Electrical, Control and Communication Engineering, vol. 2, no. 1, pp. 14-19, Jan. 2013, ISSN 2255-9140.

[7] Steigerwald, R.L., "Power electronic converter technology," Proceedings of the IEEE, vol.89, no.6, pp.890,897, Jun 2001.

[8] Steigerwald, R.L.; De Doncker, R.W.; Kheraluwala, M.H., "A comparison of high-power DC-DC soft-switched converter topologies," IEEE Transactions on Industry Applications, vol.32, no.5, pp.1139,1145, September/October 1996.

[9] Steigerwald, R.L., "A comparison of half-bridge resonant converter topologies," Power Electronics, IEEE Transactions on, vol.3, no.2, pp.174,182, April 1988.

[10] Bhat, A. K S, "Analysis and design of LCL-type series resonant converter," IEEE Transactions on Industrial Electronics, vol.41, no.1, pp.118-124, February 1994.

[11] Badstuebner, U.; Biela, J.; Kolar, J.W., "Power density and efficiency optimization of resonant and phase-shift telecom DC-DC converters," Twenty-Third Annual IEEE Applied Power Electronics Conference and Exposition. APEC 2008. pp. 311-317, 24-28 February 2008.

[12] Severns, Rudolf P., "Topologies for three-element resonant converters," IEEE Transactions on Power Electronics, vol.7, no.1, pp.89-98, January 1992.

[13] Yang, B.; Lee, F.C.; Zhang, A.J.; Guisong Huang, "LLC resonant converter for front end DC/DC conversion," Seventeenth Annual IEEE Applied Power Electronics Conference and Exposition. APEC 2002. vol.2, pp.1108-1112 vol.2, 2002.

[14] Yeh Ting; de Haan, S.; Ferreira, J.A., "A DC-DC Full-Bridge Hybrid Series Resonant Converter enabling constant switching frequency across wide load range," Power Electronics and Motion Control Conference (IPEMC), 2012 7th International, vol.2, pp.1143-1150, 2-5 June 2012
[15] Roasto, I.; Vinnikov, D.; Jalakas, T.; Zakis, J.; Ott, S.: Experimental study of shoot-through control methods for qZSI-based DC/DC converters, Proc. of SPEEDAM '10 Symposium, 14-16 June 2010, pp. 29-34.

[16] Honnyong Cha; Peng, F.Z.; DongWook Yoo, "Z-source resonant DCDC converter for wide input voltage and load variation," 2010 International Power Electronics Conference (IPEC), pp.995-1000, June 21-24, 2010.

[17] Zakis, J.; Vinnikov, D.; Bisenieks, L. "Some Design Considerations for Coupled Inductors for Integrated Buck-Boost Converters", III International Conference on Power Engineering, Energy and Electrical Drives POWERENG 2011, pp. 1-6, 2011.

[18] Chan, H.L.; Cheng, K.W.E.; Cheung, T.K.; Cheung, C.K., "Study on Magnetic Materials Used in Power Transformer and Inductor", 2nd International Conference on Power Electronics Systems and Applications ICPESA 2006, pp. 165-169, 12-14 Nov. 2006.

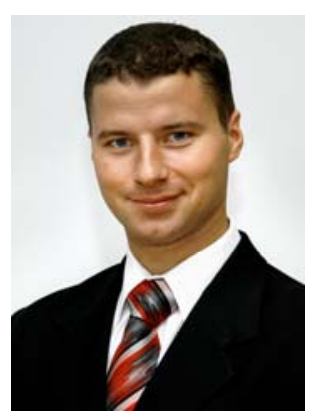

Janis Zakis (M'10) received B.Sc., M.Sc. and Dr.Sc.ing. in electrical engineering from Riga Technical University, Riga, Latvia, in 2002, 2004 and 2008, respectively.

$\mathrm{He}$ is presently a Senior Researcher in the Institute of Industrial Electronics and Electrical Engineering, Riga Technical University.

He has over 20 publications and is the holder of one Utility Model in power converter design. His research interests include flexible ac transmission systems (FACTS), simulation of power systems, switching mode power converters, applied design of power converters

and energy storage systems.

Riga Technical University, Institute of Industrial Electronics and Electrical Engineering. Address: Kronvalda 1, LV1048, Riga, Latvia; janis.zakis@ieee.org

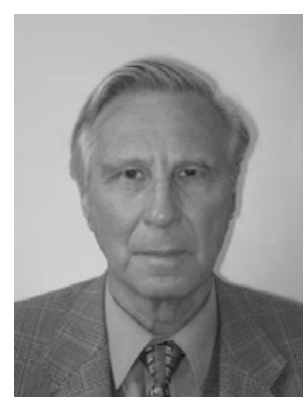

Ivars Rankis, professor, Hab.Dr.sc.eng. He graduated from Riga Polytechnical Institute in 1960 as engineer-electromechanic. Defended his first degree of Dr.sc. (candidate of technical sciences) in 1970. Defended his second degree Hab.Dr.sc.eng. in 1992 at Riga Technical University. From 1958-1966 he worked as engineer at Riga Electrical Machine Building Company. From 1966 he started studies as doctoral student, and from 1970 - as teacher of different subjects of electrical engineering at Riga Technical University. Research interests are connected with power electronics and industrial automation. Presently he is professor at the Department of Industrial Electronics and Electrical Technologies of Riga Technical University.

Riga Technical University, Institute of Industrial Electronics and Electrical Engineering. Address: Kronvalda 1, LV1048, Riga, Latvia; phone +37167089917, rankis@eef.rtu.lv

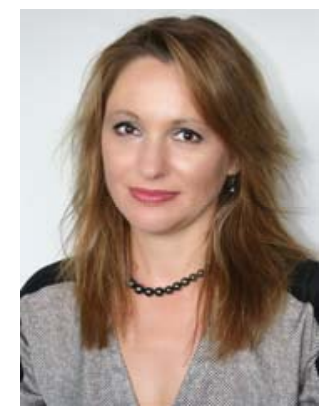

Liisa Liivik, received Dipl.-Eng, M.Sc. in Electrical Engineering from the Department of Electrical Drives and Power Electronics, Tallinn University of Technology, Tallinn, Estonia, in 1998 and 2000, respectively. She is currently working toward the Ph.D. degree at the Department of Electrical Engineering.

From 2002 to 2007, she was a lecturer in the Department of Electrical Drives and Power Electronics, Tallinn University of Technology. Her teaching areas included basics of measurement engineering and numerical calculations in electrotechnics. Her fields of interest are: research, design and simulation of switch mode converters for distributed power generation systems.

She received an award (2nd place) for her master thesis "Numerical Calculations of Electrotechnics" from Estonian Academy of Sciences and is author or co-author of more than 10 scientific papers and 1 book.

Tallinn University of Technology, Department of Electrical Engineering. Address: Ehitajate tee 5, 19086 Tallinn, Estonia; liisa.liivik.ee@ieee.org 